\title{
Adverse Consequences of Alcohol Consumption: A Preliminary Study
}

\section{"Corresponding author}

Rajesh Singh Yadav, PhD

Assistant Professor

Department of Criminology and

Forensic Science

School of Applied Sciences

Dr. Harisingh Gour Central University

Sagar, MP 470 003, India

Tel. +91-7582-264122

Fax: +91-7582-264163

E-mail: razitrc@gmail.com

Volume 1 : Issue 1

Article Ref. \#: 1000TFMOJ1105

\section{Article History \\ Received: July $30^{\text {th }}, 2016$ \\ Accepted: September $5^{\text {th }}, 2016$ \\ Published: September $7^{\text {th }}, 2016$}

\section{Citation}

Pahade N, Kori RK, Yadav S, Yadav RS. Adverse consequences of alcohol consumption: A preliminary study. Toxicol Forensic Med Open J. 2016; 1(1): 24-31. doi: 10.17140/ TFMOJ-1-105

\section{Copyright}

(C2016 Yadav RS. This is an open access article distributed under the Creative Commons Attribution 4.0 International License (CC BY 4.0), which permits unrestricted use, distribution, and reproduction in any medium, provided the original work is properly cited.

\author{
Neha Pahade, MSc'; Rajesh Kumar Kori, MSc'; Sarvendra Yadav, PhD²; Rajesh Singh \\ Yadav, $\mathrm{PhD}^{1 *}$
}

${ }^{1}$ Department of Criminology and Forensic Science, School of Applied Sciences, Dr. Harisingh
Gour Central University, Sagar, MP 470003, India

${ }^{2}$ Department of Anthropology, School of Applied Sciences, Dr. Harisingh Gour Central

University, Sagar, MP 470003, India

\section{ABSTRACT}

Alcohol is a depressant drug which slows down the activity of the central nervous system (CNS) and cause health related problems associated with various positive and negative social experiences. It has both pharmacological and toxic effects on mind and other organs of the human body. In spite of the fact that alcohol is addictive and injurious to health, more than 2 billion chronic alcoholics prevail throughout the world and the number is alarmingly increasing with the addition of new drinkers including teenagers every year. At the same time, young women are found to be more vulnerable towards the adverse consequences of alcohol consumption due to their intrinsic physical differences than men. In recent years, a drinking culture has been socially accepted among the women and it is a matter of great concern among the health scientists. Alcoholism sees as the world's highly prevalent public health problem and therefore it is a serious issue, not confined to any group, culture or country. In view of increasing incidences of alcohol consumption in India and other countries associated with health related and social problems, the present study is carried out to assess the consumption pattern of alcohol in a selected population and try to understand the ill-effects of this social malice on the drinker's social behavior.

KEYWORDS: Alcohol; Health effects; Social problems; Criminal behavior; Addiction.

\section{INTRODUCTION}

Alcohol is generally known as ethyl alcohol which is a low molecular weight hydrocarbon derived from the fermentation of sugars and cereals. The term toxic alcohol referred to isopropanol, methanol and ethylene glycol. It is a sedative hypnotic drug which affects the CNS to cause depression and alter the mood and behavior. Alcohol intoxication is also called as drunkenness which is induced by the ingestion of alcohol and it causes a feeling of well-being, self-confidence, talkativeness and excitement. ${ }^{1,2}$ Addiction is a progressive and incurable disease, which affects physical, mental and spheres of human beings, characterized by inability to control their actions over the use of alcohol and other sedatives. The factors including psychological, genetic and behavior can all contribute to having this disease. There is no such effective remedy for this ever growing and frightening disease. ${ }^{3,4}$ The major forms of this dependence are either inability to stop drinking before drunkenness is achieved, or inability to abstain from drinking because of the withdrawal symptoms. ${ }^{5}$ Alcohol is remained to be one of the most common psychoactive substances which have been used for recreational, medicinal and ceremonial purposes for at least 10 thousand years. ${ }^{6}$ Earlier, the intake of alcohol was believed to relief from stress but now it is widely accepted fact that alcohol consumption, even at low amount is associated with heart problems and mortality in middle aged and older adults. The involvement of alcohol in numerous premature deaths due to disease, accidents and violence has been reported every year. World Health Organization (WHO $)^{7}$ reported that $4 \%$ of the global burden of disease is attributable to alcohol and it is the third leading cause of death and disability in developed countries, after tobacco and hypertension. More than 8 million Ameri- 
cans are believed to be dependent on alcohol and up to $15 \%$ of the population is considered at risk. Studies have also revealed that more than half of all trauma patients are intoxicated with ethanol at the time of admitted to the hospital. In a report from US Poison Control Centers, 219 major outcomes and 15 deaths were reported from 6026 single exposures to ethanol in beverages in 2014. ${ }^{8}$ The harmful consequences of alcohol, including injury to physical health, psychological well-being and relationships cause an impact on all facets of society. At the same time, moderate alcohol consumption has certain health benefits like beneficial influence on coronary heart disease, stroke and diabetes mellitus ${ }^{9}$ while excessive chronic drinking resulting in alcohol toxicity including mild to moderate tremors, irritability, anxiety and agitation. ${ }^{10,11}$ There has been a marked increase of female alcoholics worldwide including India in recent years. ${ }^{7}$ It acts as a teratogen and the consumption of heavy alcohol during pregnancy may lead to fetal alcoholic syndrome. ${ }^{11}$ Behavioral and cognitive deficits have also been reported even at low-levels of prenatal alcohol exposure which further suggested that consumption of alcohol is not safe in pregnancy. ${ }^{7}$ Hangover generally reported by the drinkers, can be characterized by the assemblage of unpleasant physical and mental symptoms, including headache, fatigue, redness of the eyes, thirst, rapid heartbeat, tremor, sweating, dizziness, vertigo, depression, anxiety and irritability. Multiple factors such as the effects on urine production, gastrointestinal, blood sugar concentration, sleep pattern, biological rhythms have been suggested for the onset of hangover. ${ }^{12}$

Alcohol is rapidly absorbed from the gastric mucosa $(20 \%)$ and small intestine $(80 \%)$ and reached at a peak concentration 20-60 minutes after ingestion into the bloodstream where it affects almost every organ in the body, but the brain is quite vulnerable. In the liver, it is oxidized to acetaldehyde by alcohol dehydrogenase and coenzyme nicotinamide adenine dinucleotide. This acetaldehyde converted into acetic acid, which is further undergoes oxidation to carbon dioxide and water. ${ }^{13}$ Experimental studies have shown the importance of situational factors, setting and social context in determining the adverse health effects and social consequences of drinking. The social consequences, including family problems, stranger violence, non-traffic injuries, social interaction and attempted suicide have not received greater attention as problems associated with alcohol. The issues, mainly related with the long-term drinking and driving have dominated public discourse on alcohol related problems. A positive association has been observed in chronic consumption of alcohol and suicide. ${ }^{14}$ There are various ways through which alcohol consumption may lead to suicide as it may develop suicidal ideation into action and also provide motivation to carry out a suicidal attempt. ${ }^{15}$ Further, impaired decision making and difficulties in problem solving ability may trigger a person to commit suicide as they think that it is the only solution of their problems. There are about an estimated 2 billion alcoholics worldwide and this number is increasing with added new drinkers every year including teenagers. Due to the consumption of alcohol and associated adverse health effects, it ranks among the world's major threats to human health and safety. ${ }^{7}$ According to WHO data, alcohol abuse leads to the death of 3.3 million people every year and the death of 4.9 million people were reported in $2010 .^{7}$ It also leads to 25 percent of the road accidents and is a major contributor in domestic violence and family disputes. ${ }^{16}$ Due to increasing incidences of alcohol intoxications and adverse health effects associated with it, the present study is carried out to assess the consumption pattern of alcohol in a selected population and try to understand the ill effects due to the alcohol consumption associated with abnormal social behavior and problems.

\section{MATERIALS AND METHODS}

The consumption of alcohol has been considered as social evil and there should be some measures to eradicate this evil. In the forensic science, the knowledge of alcohol and its adverse effects on body and collection and preservation of samples related with alcohol intoxication will be important for law enforcement agencies for the effective implementation of law and order. Alcohol intoxication and addiction can have adverse health and socio-economic effects on the individual drinker and also the whole environment. At the same time, the individuals other than the drinkers can also get affected by drinker's unwarranted acts like traffic accidents, aggression and violent behavior. These undesirable acts create unnecessary pressure on public resources viz criminal justice, health care and other social institutions. The study pertaining to the pattern of alcohol consumption and associated adverse social consequences is needed, especially when the consumption of alcohol is increasing in the women and teenagers. It is creating an alarming situation in the public sphere. Hence, it is desirable to regulate the consumption of alcohol in our youngsters to prevent the alcohol dependency and protect our society from this malice. Although the analysis of alcohol in a biological sample is necessary at the molecular level, but the preliminary studies, related to its intoxication and consumption pattern also useful in disseminating the information about its harmful impact onto the society.

To fulfill the aforesaid objectives, an empirical study was carried out in Sagar District of Madhya Pradesh, India. A questionnaire was prepared with 28 items, in which individual's details including age, sex, socio-economic profile along with the background, consumption pattern of different alcoholic drinks and associated ailments were in-listed. The questions related to the behavior and other experiences during and after intoxication and adverse health effects in term of disease or toxicity were also included in the questionnaire. The random sampling method was employed to collect quantitative data pertaining to the alcohol consumption and associated consequences in the studied population.

The study was conducted between the month of August and November, 2015 with the sample size of 150 individuals. The questionnaire was distributed among the selected volunteers and they were asked to fill the answer without disclosing their identity. The volunteers were from age groups of 10-50 years 
and from different socio-economic background. Most of the volunteers were from male category and literate. Total 150 personal interviews were conducted in which questions related to individual habits, experiences, causes of alcoholism, associated diseases, weak performances on occupations, interventions in this regard were discussed. Questions related to the domestic violence, involvement in illegal activities and withdrawal symptoms were also discussed thoroughly. Data were collected and scores of individual questionnaire were tabulated for the analysis. After analyzing the data of percentage changes, specific inferences were made and presented in the study.

\section{RESULTS}

\section{Socio-Economic Background of the Drinkers}

The socio-economic background of the participants has been analyzed and represented in Table 1 . In the present study out of total sample collected, 91\% participants were male, while 9\% participants were female. Forty-three percent of the participants were from rural backgrounds and 57\% were from urban background. Those who participated in the study, $48 \%$ were from the joint family and $52 \%$, were from nuclear family system. The economic status of the person has been represented in lower income, middle income and higher income class where we have found that the largest drinkers were from lower income group $(55 \%)$ while educational background represents that the literate have the highest percentage of alcohol consumed (81\%).

Reasons for alcohol consumption: There is no specific reason which can be assigned why people start drinking. There are a variety of situations in which people start consuming alcohol. In the present study, we have reported that the most of the people consumed alcohol because of stress (46\%), happiness (62\%), depression $(17 \%)$ and other reasons $(4 \%)$. The details are represented in Figure 1.

Initial age of alcohol consumption: The maximum unsafe use of alcohol has been reported in the populations from the age of 15-29 years. The study has been carried out on 150 persons of different age group such as 10-11, 11-15, 16 and above, in which $3 \%$ were in the age between $10-11,30 \%$ in between $11-15$ and $66 \%$ were in the age of between 16 and above in which they started consuming alcohol. The details are represented in Figure 2.

Adverse consequences of intoxication: The persons other than the drinkers also get affected from adverse consequences of alcohol through the traffic accident and violent behavior. Adverse health effects due to consumption of alcohol has been observed and presented in Figure 3. The study revealed that there were various situations in which drinkers mainly involved after the intoxication. These consequences include traffic accidents (34\%), law and order situation (23\%), admitted to hospital due to injury or accident $(8 \%)$ and business problem $(22 \%)$.

\begin{tabular}{|c|c|c|c|}
\hline S. No. & Participant details & Class & Percentage \\
\hline \multirow{2}{*}{1} & \multirow{2}{*}{ Gender } & Male & $91 \%$ \\
\hline & & Female & $9 \%$ \\
\hline \multirow{2}{*}{2} & \multirow{2}{*}{ Place } & Rural & $43 \%$ \\
\hline & & Urban & $57 \%$ \\
\hline \multirow{2}{*}{3} & \multirow{2}{*}{ Family type } & Nuclear & $52 \%$ \\
\hline & & Joint & $48 \%$ \\
\hline \multirow{3}{*}{4} & \multirow{3}{*}{ Economic status } & Lower & $55 \%$ \\
\hline & & Middle & $17 \%$ \\
\hline & & Higher & $28 \%$ \\
\hline \multirow{2}{*}{5} & \multirow{2}{*}{ Education } & Literate & $81 \%$ \\
\hline & & Illiterate & $19 \%$ \\
\hline
\end{tabular}

Table 1: Details of participants represented from various classes and background.

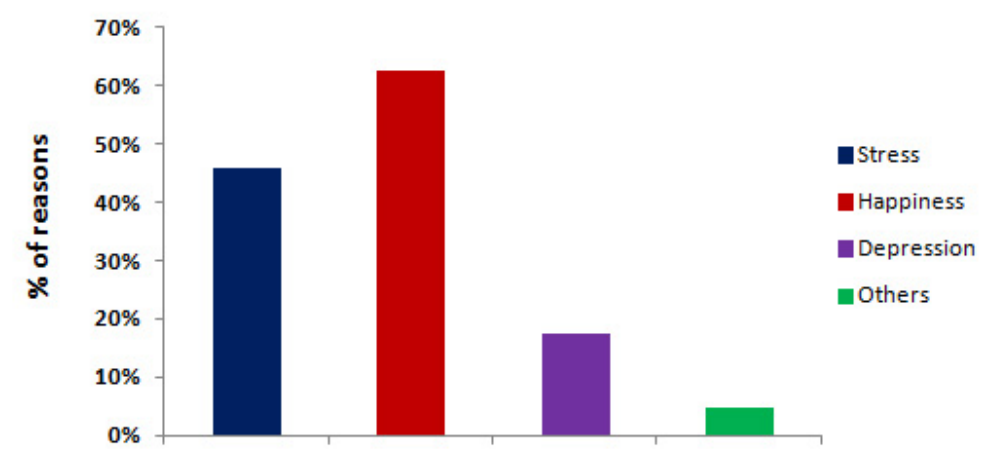

Figure 1: Various factors of alcohol consumption including stress, happiness, depression etc. 


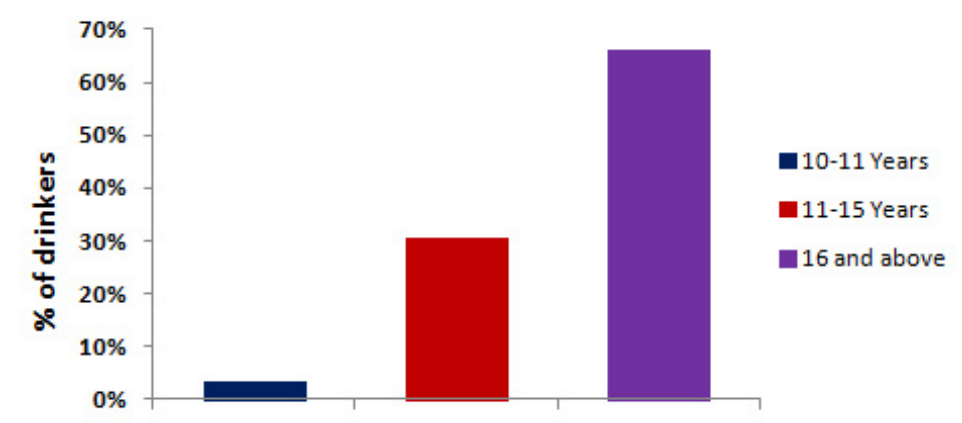

Figure 2: Initial age of starting alcohol consumption revealed the pattern of alcohol consumption and age of maximum adverse consequences.

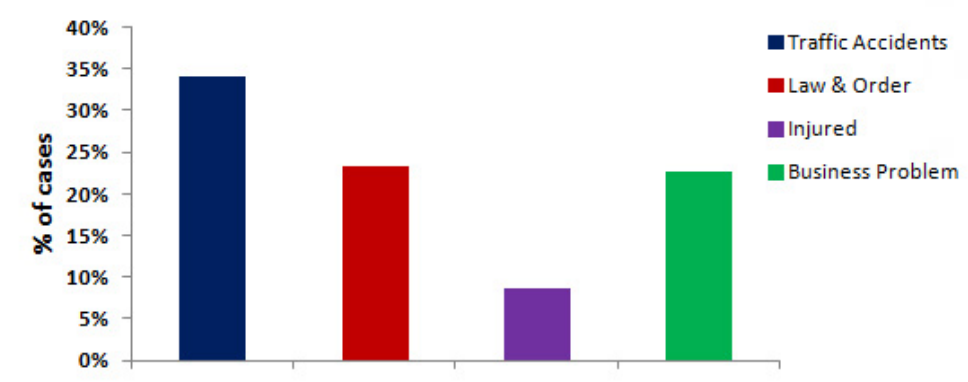

Figure 3: Adverse consequences of intoxication resulted in traffic accident and various other problems.

Impaired behavior during intoxication: The study revealed that the behavior of peoples during intoxication significantly modified. People have reported that they have been feeling bad (22\%), active in illegal activities (14\%), aggression (26\%), domestic violence $(19 \%)$ and involved in suicidal attempts $(9 \%)$. The details are represented in Figure 4.

Withdrawal symptoms of alcohol: The consumption of alcohol is addictive and it results the dependency. If drinkers will not get the alcohol at the time of their need or desire, altered mood and behavior may be shown in terms of withdrawal symptoms. The study has been revealed that the condition of the person during need or absence of alcohol such as anxiety (34\%), aggression $(32 \%)$, stealing money $(13 \%)$ and ready to perform illegal ac- tivities $(8 \%)$. The details are represented in Figure 5.

Adverse effects on health after intoxication: Alcohol intoxication leads to various effects on human health. On the basis of self assessment and questionnaire based study, it has been observed that people showed a number of effects during alcohol intoxication such as insomnia (11\%), slurred speech (46\%), vomiting $(10 \%)$, diarrhea $(9 \%)$, stomach upset $(10 \%)$, headache $(17 \%)$, breathing difficulties $(9 \%)$, distorted hearing (16\%), impaired judgment (7\%), anemia (11\%), coma (2\%) and black out (19\%). The details are represented in Figure 6.

Disease due to heavy and regular intake of alcohol: Acute and chronic alcohol consumption has been found to be largely asso-

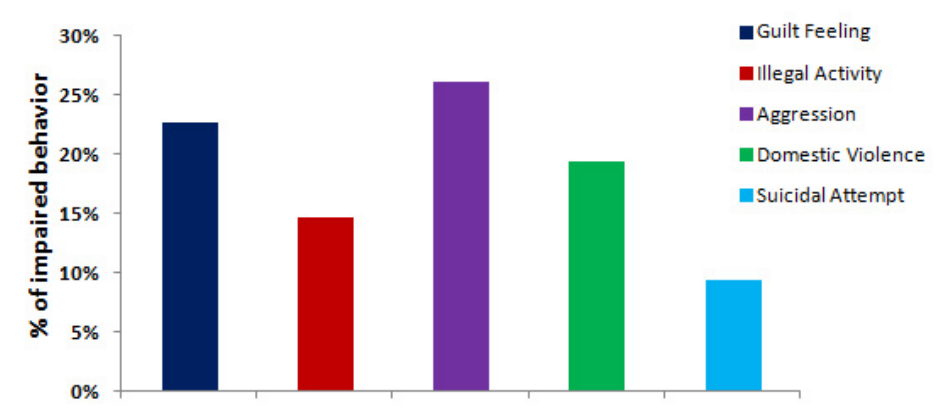

Figure 4: Behavior of persons during intoxication found to be impaired as abnormal behavior including aggression, violence and suicidal attempts. 


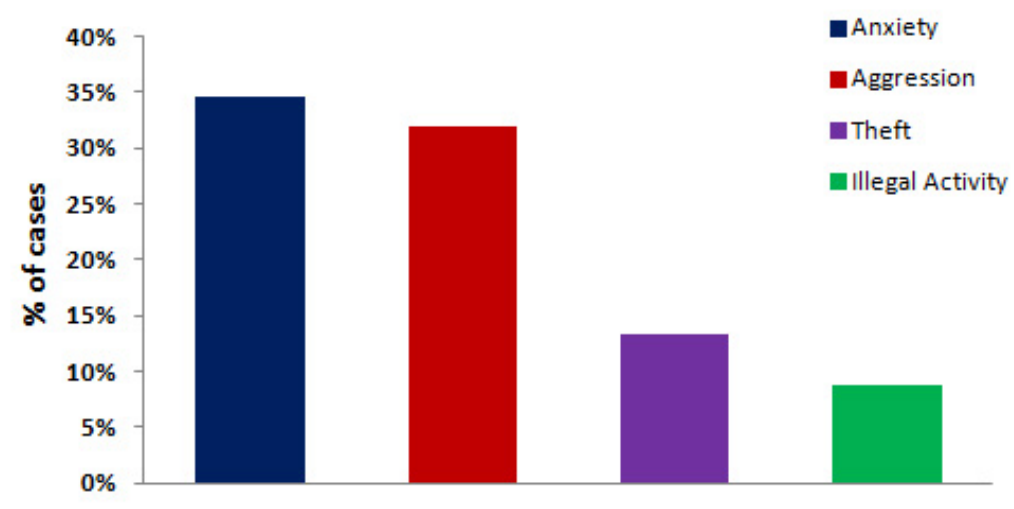

Figure 5: Withdrawal symptoms of alcohol due to lack of alcohol may resulted in altered mood and behavior conditions.

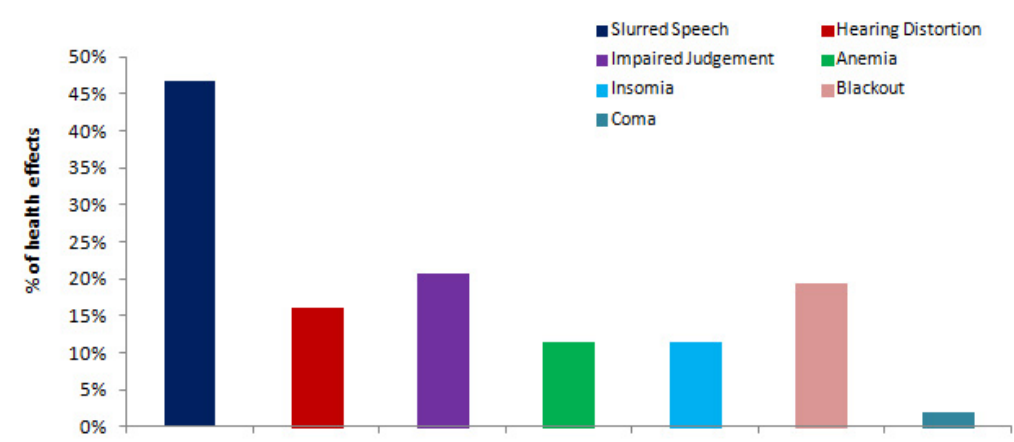

Figure 6: Adverse health effects of alcohol intoxication includes various symptomatic effects including slurred speech, insomnia, breathing difficulties, distorted hearing, anemia and others.

ciated with the various diseased conditions. In the present study, people have reported that they suffered various disease conditions, including liver problems $(16 \%)$, brain related problems $(16 \%)$, mouth or throat problem $(8 \%)$, heart related problems $(6 \%)$, blood pressure (14\%) and other problems $(12 \%)$. The details are represented in Figure 7.

Direct effects of alcohol: Direct effects of alcohol may occur in the form of hangover which may include dehydration, gastrointestinal disturbances, low blood sugar and altered sleep pattern. In the present study the direct effects of alcohol are seen in the form of diarrhea $(9 \%)$, headache $(17 \%)$, dizziness $(16 \%)$, sweating $(22 \%)$, vomiting $(10 \%)$, gastritis $(6 \%)$ and fatigue $(8 \%)$.
The problem of sweating, diarrhea, dizziness and vomiting are commonly associated with dehydration while gastrointestinal disturbances include gastritis and abdominal pain. Symptoms of fatigue are generally linked with the low blood sugar levels and altered sleep pattern. The details are represented in Figure 8.

\section{DISCUSSION}

The chronic consumption of large amount of alcohol may be a risk factor for the development of peripheral neuropathy with the sensory symptoms including numbness, paresthesias, dysesthesias, allodynia, and loss of vibration and position sense mainly in the distal lower extremities. ${ }^{17}$ It is a primary axonal neuropa-

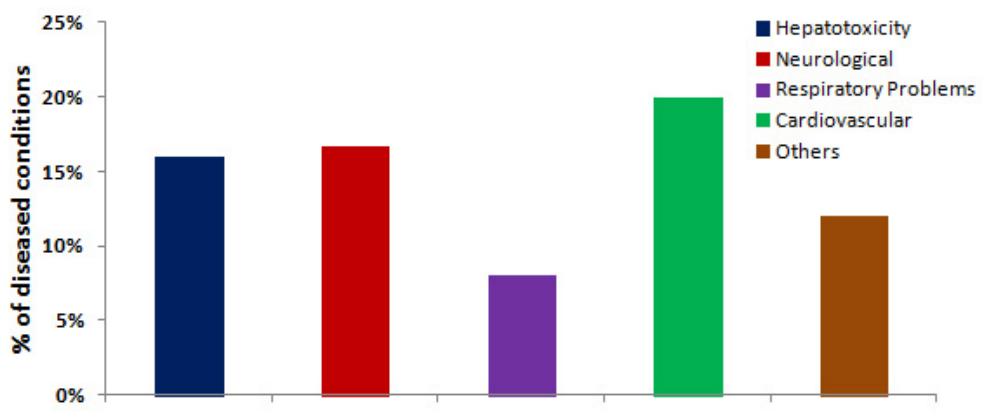

Figure 7: Diseased conditions due to chronic and acute alcohol consumption leading to the serious health related issues. 


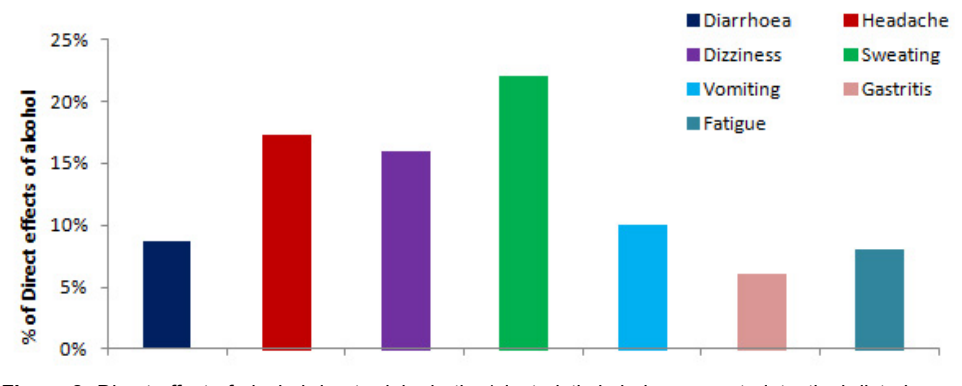

Figure 8: Direct effect of alcohol due to dehydration/electrolytic imbalance, gastrointestinal disturbances and low blood sugar levels.

thy marked by wallerian degeneration of the axons and myelin sheath neural fibers. ${ }^{18}$ Studies have also suggested that nutritional deficiencies including thiamine may be linked with the development of neuropathy in patients. The implicated mechanisms behind the neuropathy have found to link with the increased oxidative stress leading to free radical damage to the nerves. ${ }^{19,20}$ Besides, direct effects to the human body, alcohol intoxication is also associated with the social problems, including domestic violence, traffic accidents, child neglect, abuse, absenteeism in the workplace and others. ${ }^{21}$ The harmful use of alcohol becomes the leading risk factor for death in male ages from 15-59 due to the injuries, violence and diseases. ${ }^{22}$ Further, its consumption is an important cause of mortality, morbidity and social damage worldwide. The cases of drunken driving and road rage have been well established through experimental and epidemiological studies. ${ }^{9,23}$ There are various aspects of drinking through which household functioning of a family member becomes impaired. In our society, people usually drink outside the family and home and thus, affect the family duties of an individual. It also costs money and hampers economic resources to leave the other family members on the breadline. White and Chen, ${ }^{24}$ reported the linkage between drinking patterns and partner violence. They further explained that persons who heavily consumed alcohol and develop dependency are more likely to show violent behavior with their partners. In the present study, the behavior of persons after intoxication has been found to be impaired and involved in illegal activities, aggressive behavior and domestic violence.

The adverse health effects on children are also found to be associated with the alcohol use by the family member or caretaker. Youngster has been found to have at a greater risk to develop alcohol dependence due to their immature brain as compared to adult. ${ }^{25} \mathrm{Few}$ drinkers have been reported suicidal tendencies, as they thought that it is the only solution of their problems. It is further associated with the damage to the brain regions involved in learning and memory, decision making and reasoning. ${ }^{26}$ An injury in the brain parts may lead to the functional abnormalities which can further associated with the lower academic performance and affect the learning and cognitive functions..$^{27,28}$ Toumbourou et $\mathrm{al}^{29}$ reported that unsafe use of alcohol caused approximate $31.5 \%$ of deaths among $15-29$ year persons worldwide. In the present study, we have found that the maximum drinkers started drinking at the age of 16 years or above but the percentage of drinkers under the age of 15 are also remarkable and indicates an alarming situation. The adverse consequences of alcohol intoxication such as slurred speech, vomiting, diarrhea, stomach upset, headache, breathing difficulties, distorted hearing, impaired judgment, anemia, insomnia, coma and blackout have been observed in the present study. Further, withdrawal symptoms in the absence of alcohol, including anxiety, aggression, stealing money and involvement in illegal activities have also been observed.

The consumption of alcohol in women is reported less frequently than men and therefore women are at lower risks of adverse health consequences than male drinkers. Due to the physical difference, the metabolism of alcohol in women occurs differently than men and hence the risks including liver cirrhosis, alcohol dependence linked with alcohol consumption are often augmented for women. ${ }^{30}$ The incidences of breast cancer have been reported in drinkers who consumed moderate to heavy drink. ${ }^{31}$ Smith-Warner et $\mathrm{al}^{32}$ suggested that low consumption of alcohol (one drink per day) is associated with a $9 \%$ increase in the risk of developing breast cancer relative to non-drinkers, while consuming higher quantity may lead to risk of breast cancer to $41 \%$. Consumption of alcohol during pregnancy may cause complication of pregnancy and delivery associated with spontaneous abortion and stillbirth. ${ }^{33}$ It may also affect the developing fetus and cause neurological disorders in the child. ${ }^{34,35}$ In the present study, the ratio of consumption of alcohol in women was found less compared to men probably because of the patriarchal setup in which women are supposed to be inside the house and their freedom is restricted in many ways. Adverse consequences of alcohol in terms of disease conditions including hepatotoxicity, neurological problems, anxiety, cardiovascular diseases and others have also been observed in the present study indicating the adverse health effects of alcohol consumption.

\section{CONCLUSIONS}

We can conclude from the present study that in the studied population group the persons were found consuming alcohol. Due to the consumption of such products their overall performance was also affected. There was the high number of cases reported re- 
lated to the road accident and disputes in the family. The middle class population was found to be largely consumed alcohol, primarily for pleasure and euphoria. There is a need for awareness regarding the ill-effects of alcohol consumption and people should be made aware about the social, economical and health consequences of alcoholism. It is needed to survey the general population with specific groups in a systematic manner in order to monitor changes in levels of alcohol consumption and drinking patterns. The monitoring of early alcohol use can help to prevent the development of alcohol dependence and protect our society from its adverse consequences.

\section{ACKNOWLEDGEMENT}

The authors are thankful to Dr. Harisingh Gour Central University, Sagar, MP, India, for providing the opportunity to work and their support and interest. Authors are also thankful to the volunteers participated in the present work and for their support and interest.

\section{CONFLICTS OF INTEREST}

The authors declare that they have no conflicts of interest.

\section{REFERENCES}

1. National Institute on Alcohol Abuse and Alcoholism (NIAAA). Health risks and benefits of alcohol consumption. Alcohol Res Health. 2000; 24(1): 5-11. Web site. http://pubs.niaaa. nih.gov/publications/arh24-1/05-11.pdf. Accessed July 29, 2016

2. Ronksley PE, Brien SE, Turner BJ, Mukamal KJ, Ghali WA. Association of alcohol consumption with selected cardiovascular disease outcomes: A systematic review and meta analysis. BMJ. 2011; 342: d671. doi: 10.1136/bmj.d671

3. Lieberman D. Children of alcoholics: An update. Curr Opin Pediatr. 2000; 12(4): 336-340. Web site. http://journals.lww. com/co-pediatrics/Abstract/2000/08000/Children_of_alcoholics_an_update.9.aspx. Accessed July 29, 2016

4. Wetterling T, Junghanns K. Psychopathology of alcoholics during withdrawal and early abstinence. Eur Psychiatry. 2000; 15(8): 483-488.

5. Harwood H, Fountain D, Livermore G. The economic costs of alcohol and drug abuse in the United States 1992 (updated for 1998). NIH. 2000; 98-4327.

6. Sinkiewicz W, Weglarz M. Alcohol and wine and cardiovascular diseases in epidemiologic studies. Przegl Lek. 2009; 66(5): 233238. Web site. http://europepmc.org/abstract/med/19739580. Accessed July 29, 2016

7. WHO. Alcohol, Gender and Drinking Problems: Perspectives from Low and Middle Income Countries. World Health Orga- nization, Department of Mental Health and Substance Abuse. 2005. Web site. http://www.who.int/substance_abuse/publications/alcohol_gender_drinking_problems.pdf. Accessed July 29, 2016

8. Mowry JB, Spyker DA, Brooks DE, McMillan N, Schauben JL. 2014 Annual Report of the American Association of Poison Control Centers' National Poison Data System (NPDS): $32^{\text {nd }}$ Annual Report. Clin Toxicol (Phila). 2015; 53(10): 962-1147. doi: $10.3109 / 15563650.2015 .1102927$

9. Rehm J, Room R, Monteiro M, et al. Alcohol as a risk factor for global burden of disease. Eur Addict Res. 2003; 9: 157-164. doi: $10.1159 / 000072222$

10. Kessler RC, Nelson CB, Mcgonagle KA, Edlund MJ, Frank RG, Andleaf PJ. The epidemiology of co-occurring addictive and mental disorders: Implications for prevention and service utilization. Am J Orthopsychiatry. 1996; 66(1): 17-31. doi: $10.1037 / \mathrm{h} 0080151$

11. Rehm J, Baliunas D, Borges GL, et al. The relation between different dimensions of alcohol consumption and burden of disease: An overview. Addiction. 2010; 105(5): 817-843. doi: 10.1111/j.1360-0443.2010.02899.x

12. Lemon J, Chesher G, Fox A, Greeley J, Nabke C. Investigation of the hangover effects of an acute dose of alcohol on psychomotor performance. Alcohol Clin Exp Res. 1993; 17(3): 665-668. doi: 10.1111/j.1530-0277.1993.tb00816.x

13. Cederbaum AI. Alcohol Metabolism. Clin Liver Dis. 2012; 16(4): 667-685. doi: 10.1016/j.cld.2012.08.002

14. Ramstedt M. Alcohol-related mortality in 15 European Countries in the postwar period. Eur J Popul. 2002; 18: 307323. doi: 10.1023/A:1021105124283

15. Sher L, Sperling D, Zalsman G, Vardi G, Merrick J. Alcohol and suicidal behavior in adolescents. Minerva Pediatr. 2006; 58(4): 333-339. Web site. http://europepmc.org/abstract/ med/17008841. Accessed July 29, 2016

16. Babor TF, Caetano R, Casswell S, et al. Alcohol: No ordinary commodity. Oxford, UK: Oxford University Press; 2003: 301.

17. Alvarez P, Ferrari LF, Levine JD. Muscle pain in models of chemotherapy-induced and alcohol-induced peripheral neuropathy. Ann Neurol. 2011; 70(1): 101-109. doi: 10.1002/ana.22382

18. Yerdelen D, Koc F, Uysal H. Strength-duration properties of sensory and motor axons in alcoholic polyneuropathy. Neurol Res. 2008; 30(7): 746-750. doi: 10.1179/174313208X291694

19. McDonough KH. Antioxidant nutrients and alcohol. Toxicology. 2003; 189(1-2): 89-97. 
20. Montoliu C, Valles S, Renau-Piqueras J, Guerri C. Ethanolinduced oxygen radical formation and lipid peroxidation in rat brain: Effect of chronic alcohol consumption. JNeurochem. 1994; 63(5): 1855-1862. doi: 10.1046/j.1471-4159.1994.63051855.x

21. Cosci F, Schruers KR, Abrams K, Griez EJ. Alcohol use disorders and panic disorder: A review of the evidence of a direct relationship. J Clin Psychiatry. 2007; 68(6): 874-880. Web site. http:/www.psychiatrist.com/jcp/article/Pages/2007/v68n06/ v68n0608.aspx. Accessed July 29, 2016

22. Rehm J, Mathers C, Popova S, Thavorncharoensap M, Teerawattananon Y, Patra J. Global burden of disease and injury and economic cost attributable to alcohol use and alcohol-use disorders. Lancet. 2009; 373(9682): 2223-2233. doi: 10.1016/S01406736(09)60746-7

23. Sindelar H, Barnett NP, Spirito A. Adolescent alcohol use and injury. A summary and critical review of the literature. $\mathrm{Mi}$ nerva Pediatr. 2004; 56(3): 291-309.

24. White HR, Chen PH. Problem drinking and intimate partner violence. J Stud Alcohol. 2002; 63: 205-214. doi: 10.15288/ jsa.2002.63.205

25. Grant BF. Estimates of U.S. children exposed to alcohol abuse and dependence in the family. Am J Public Health. 2000; 90(1): 112-115. Web site. http://www.ncbi.nlm.nih.gov/pmc/articles/PMC1446120/pdf/10630149.pdf. Accessed July 29, 2016

26. Zeigler D, Wang CC, Yoast RA, et al. The neurocognitive effects of alcohol on adolescents and college students. Preventive Medicine. 2005; 40(1): 23-32.

27. Borsari B, Murphy JG, Barnett NP. Predictors of alcohol use during the first year of college: Implications for prevention. $\mathrm{Ad}$ dictive Behaviors. 2007; 32(10): 2062-2086. doi: 10.1016/j.addbeh.2007.01.017

28. Kumari M, Holmes MV, Dale CE, et al. Alcohol consumption and cognitive performance: A Mendelian randomization study. Addiction. 2014; 109(9): 1462-1471. doi: 10.1111/add.12568

29. Toumbourou J, Stockwell T, Neighbors C, Marlatt G, Sturge J, Rehm J. Interventions to reduce harm associated with adolescent substance use. Lancet. 2007; 369: 1391-1401. doi: 10.1016/ S0140-6736(07)60369-9

30. Edwards G, Marshall E, Cook CC. The Treatment of Drinking Problems. $4^{\text {th }}$ ed. Cambridge, UK: Cambridge University Press; 2003.

31. Baan R, Straif K, Grosse Y, et al. WHO International Agency for Research on Cancer Monograph Working Group. Carcinogenicity of alcoholic beverages. Lancet Oncol. 2007; 8(4): 292293.
32. Smith-Warner S, Spiegelman D, Yaun S, et al. Alcohol and breast cancer in women: A pooled analysis of cohort studies. JAMA. 1998; 279: 535-540. doi: 10.1001/jama.279.7.535

33. Kesmodel U, Wisborg K, Olsen S, Henriksen T, Secher N. Moderate alcohol intake during pregnancy and the risk of stillbirth and death in the first year of life. Am J Epidemiol. 2002; 155: 305-312. doi: 10.1093/aje/155.4.305

34. Sayal K, Heron J, Golding J, Emond A. Prenatal alcohol exposure and gender differences in childhood mental health problems: A longitudinal population-based study. Pediatrics. 2007; 119(2): 426-434. Web site. http://pediatrics.aappublications.org/content/119/2/e426.long?sso=1\&sso_redirect_co unt $=1 \&$ nfstatus $=401 \&$ nftoken $=00000000-0000-0000-0000$ $000000000000 \&$ nfstatusdescription $=$ ERROR $\% 3 \mathrm{a}+\mathrm{No}+$ local $+\mathrm{t}$ oken. Accessed July 29, 2016

35. Willford J, Leech S, Day N. Moderate prenatal alcohol exposure and cognitive status of children at age 10. Alcohol Clin Exp Res. 2006; 30: 1051-1059. doi: 10.1111/j.15300277.2006.00119.x 